\title{
Progress on the European Working Time Directive (EWTD) and New Deal negotiations
}

\author{
Andrew F Goddard
}

Two years since its full implementation, the European Working Time Directive (EWTD) continues to be seen as one of the main culprits in the disintegration of clinical medicine in UK hospitals. Interestingly, the rest of the European Union (EU) is also less than happy with the restrictions the directive creates, especially as it applies to doctors. There is therefore a considerable appetite for revisiting the directive in the EU, and the European Commission (EC) is currently running a consultation process for 'social partners' to understand the appetite for such revision and what it should entail. ${ }^{1}$

'Social partners' in this context are representatives of trade unions and employers, and for health these are the European Public Services Union (EPSU) and the European Hospital and Healthcare Employers Association (HOSPEEM). The UK representatives for these organisations are the NHS Confederation European Office for HOSPEEM and UNISON, UNITE, the Royal College of Nursing and Royal College of Midwives for EPSU. Although not official social partners, several UK professional organisations were also consulted by the Commission given the relevance of the EWTD to hospital practice. The Royal College of Physicians (RCP) has played a leading role in this process, taking part in consultation meetings and submitting responses to the social partner process and the EC. ${ }^{2}$

This consultation asks whether the EWTD could undergo radical revision or whether revision of the specific areas of the definition of working time and the timing of compensatory rest (ie the SiMAP and Jaeger rulings ${ }^{3}$ ) would allow the directive to be more workable. The Commission has made it clear that it supports the right of an individual to opt-out and that there is no negotiation to be had over increasing the total working time beyond 48 hours. The consultation has arisen as much because of member states having to make use of the opt-out clause to allow the directive to be applied and there is concern that individuals may be pressurised to opt-out.

The responses from different UK organisations were interesting and summarise what may or may not be possible in both the UK and the EU as a whole. In short, there is very little enthusiasm for attempting a total redrafting of the directive. This is unsurprising given the failure of previous attempts in the EU to get any agreement around this. There is, reassuringly, general agreement that a focused reworking of the directive around SiMAP and Jaeger will be worthwhile and have many benefits.

Andrew F Goddard, director, Medical Workforce Unit, Royal College of Physicians, London
The RCP response provided focused solutions demonstrating how changes to SiMAP and Jaeger would solve many problems of running acute medicine in a 48 -hour working week. The RCP has called for relaxation as to the timing of compensatory rest for both consultants and trainees to prevent short notice cancellation of activity and allow internal locums to cover for sickness absence. It has asked for resident 'on-call' time only to be counted as working time when the doctor is working and stressed that individual opt-out must remain.

The NHS Confederation response mirrors that of the RCP. ${ }^{4}$ It makes clear the difficulties in providing a 24-hour service under the constraints of the EWTD and the importance of providing adequate training experience. It also emphasises the risks to patient care if compensatory rest rules are applied to the letter.

The Royal College of Surgeons of England (RCS) agrees that the issues of on-call time and compensatory rest are important, but pushes for a sectoral exclusion of hospital doctors and doctors-in-training from the directive which would allow these two groups to work beyond 56 hours. ${ }^{5}$ There is considerable resistance from the Commission to such a sectoral opt-out and this seems an unlikely outcome from this consultative process, even though it is attractive.

The British Medical Association (BMA), perhaps alone among the responses, is 'satisfied with the EWTD as it currently stands'. ${ }^{6}$ It believes that a redesign of training programmes will allow many of the issues of loss of training due to the 48-hour week to be resolved. It strongly opposes any change to the definition of inactive on-call time as working time and believes that the compensatory rest legislation is unworkable because of lack of clarity as to the implementation of the regulation rather than the principle.

Such a hard-line stance on the EWTD by the BMA is bad news for anyone hoping for a successful renegotiation of the New Deal on junior doctors' hours. The New Deal is, if anything, the bigger problem for hospitals trying to run a 24-hour hospital service due to huge financial penalty of employing junior doctors over 48 hours a week. Thus, while many doctors may want to work 56 hours a week (and opt-out to do so) their employers cannot afford for them to do so. Furthermore, even if the RCS is successful in getting a sectoral opt-out it may just act as a cosmetic result if the New Deal is not renegotiated. The UK government is aware of the issues with the New Deal and has hinted that it would consider renegotiation. Without the BMA's support, though, such renegotiation would be doomed to failure.

The social partners will announce the outcome of their discussions in late 2011. If agreement between the partners is 
reached, the Commission will then be able to start the legislative processes to change the directive. However, any process to get the directive change will then take a further three to four years and, if agreement is not reached, the Commission will need to decide whether to push through change without the full support of the partners. Either way, by then it will probably be too late for such changes to be helpful in the provision of acute services in the NHS.

\section{References}

1 Reviewing the working time directive. European Commission. Brussels, $\operatorname{COM}(2010)$ 801/3.
2 www.rcplondon.ac.uk/category/subject/ewtd

3 Goddard AF. Planning a consultant delivered NHS. BMJ 2010;341:c6034.

4 ww.nhsemployers.org/EmploymentPolicyAndPractice/European_ employment_policy/Pages/Working-Time-Directive.aspx

5 www.hospitaldr.co.uk/blogs/our-news/surgeons-call-for-new-trainingbased-contract-for-junior-doctors

6 www.bma.org.uk/lobbying_campaigning/euro_parliament/index.jsp

Address for correspondence: Dr AF Goddard, Medical Workforce Unit, Royal College of Physicians, 11 St Andrews Place, Regent's Park, London NW1 4LE. Email: Andrew.Goddard@derbyhospitals.nhs.uk

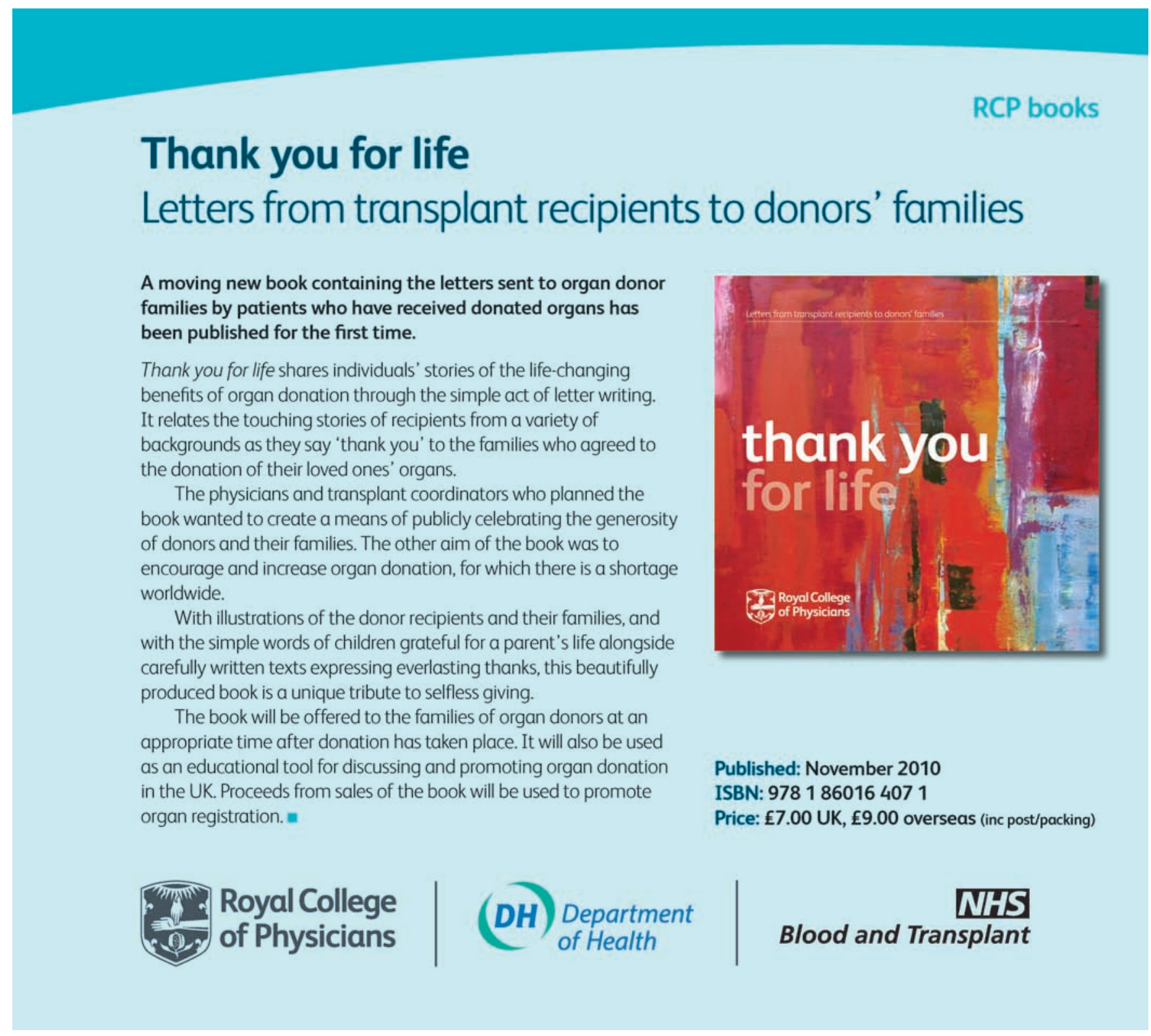

